\title{
Laboratory evaluation of the effects of triflumuron on the development of Rhodnius prolixus nymph
}

\author{
CB Mello, D Mendonça-Lopes, D Feder, CD Uzeda, RM Carneiro, MA Rocha, MS Gonzalez/+
}

Departamento de Biologia Geral, Instituto de Biologia, Universidade Federal Fluminense, Morro do Valonguinho s/n, 24001-970 Niterói, RJ, Brasil

Studies were carried out to evaluate the efficacy of the growth regulator, triflumuron (TFM) (Starycide ${ }^{\circledR}$ Sc 480 Bayer), for disrupting the development of Rhodnius prolixus fifth-instar nymph by oral, topical or continuous treatment. All treatments were able to induce high levels of mortality, delay development and molt inhibition. Oral treatment induced molt inhibition in all insects that survived at doses of $0.25,0.50$ and $5.0 \mathrm{mg} / \mathrm{mL}$ of a blood meal. The highest levels of both mortality in $24 \mathrm{~h}$ and molt inhibition were always observed after topical treatment. The lowest doses needed to obtain considerable biological effects were always observed after continuous treatment. In this way, the highest levels of mortality within 30 days were detected after continuous treatment, which also induced an extended inter-molting period, a lower number of over-aged nymphs and the highest level of molting in nymphs that survived. Moreover, the effects of TFM on insects were often displayed in a dose response manner. These results indicate that TFM acts as a potent growth inhibitor of R. prolixus nymphs and has the potential to be used in integrated vector control programs against hematophagous triatomine species.

Key words: Rhodnius prolixus - triflumuron - benzoylphenylurea - chitin synthesis inhibitor

In search of alternative methods against insect pests that would avoid the harmful effects of conventional insecticides on both the environment and human health (WHO 2006), the insect growth regulators (IGRs) of the benzoylphenylurea (BPU) family were used against a wide range of crop, pasture and forest pests (Amir \& Pevelling 2004) and also against disease vectors (Langley 1995, Rehini \& Soltani 1999, Senthil-Nathan et al. 2006). The primary mode of action of BPUs is to disrupt chitin synthesis during larval development, which is the period that determines molting inhibition and/or malformations of the cuticle (Merzendorfer 2006). Since BFUs are relatively selective towards immature life stages of arthropods and are safe for vertebrates, they are often preferred over broad-spectrum insecticides when control operations against agricultural plagues are conducted in natural and semi-natural ecosystems (Sulaiman et al. 1994).

Chagas disease (Chagas 1909) is an illness widely spread in South America that currently affects 18 million people (Garcia et al. 2007) by the dissemination by hematophagous insects such as Rhodnius prolixus. Furthermore, $R$. prolixus is traditionally used as a model for studies of insect physiology, control vector strategies and parasite vector interactions (Garcia \& Azambuja 2004). Therefore, the aim of the present work was to investigate the biological effects of different doses and treatments

Financial support: CNPq, FAPERJ, Pibic-UFF

+ Corresponding author: marcelo@ioc.fiocruz.br

Received 9 June 2008

Accepted 8 September 2008 with triflumuron (TFM) (Starycide ${ }^{\circledR}$ sc 480 Bayer) on the fifth instar nymph of $R$. prolixus and evaluate perspectives for an integrated vector control programs against blood sucking triatomine species.

Starycide $^{\circledR}$, containing $48 \mathrm{~g}$ of TFM per $100 \mathrm{~mL}$, was kindly provided by Bayer (Brazil) and directly used for the experiments using fifth-instar nymph of male $R$. prolixus (Hemiptera: Reduviidae). The insects were reared and maintained in the laboratory at $28^{\circ} \mathrm{C}$ with a relative humidity of $60-70 \%$, as described by Garcia et al. (1984). Randomly chosen insects from different experimental groups were then allowed to feed upon a membrane apparatus and submitted to the biological assays.

Following ecdysis, nymphs were starved for 25 days and then submitted to three different approaches. The control group was only fully engorged on citrated whole human blood. Doses from 0.05-5.0 mg of Starycide ${ }^{\circledR}$ per insect were used for the topical treatment and applied directly to the ventral surface of the abdomen immediately after feeding. The feeding treatment was performed by adding TFM to the blood meal at concentrations from 0.05-5.0 mg per mL. For the continuous treatment, Starycide $^{\circledR}$ was applied evenly at the bottom of a Petri dish $(\varnothing 9 \mathrm{~cm})$ in order to obtain final concentrations ranging from $0.007-0.7 \mathrm{mg} / \mathrm{cm}^{2}$ after evaporation of the solvent. Nymphs were then placed on the treated surface and covered with a Petri dish. Controls were placed in untreated Petri dishes. Only fully engorged insects were used throughout the experiments. The biological evaluation of the different treatments were recorded by weight of ingested blood, amount of excretion, toxicity (i.e., $24 \mathrm{~h}$ and 30 days mortality), intermoulting period (range), percentage of ecdysis, presence of insects that remained as over-aged nymphs for a greatly extended period (after 30 days of last feeding) and malformations of the cuticle (Rehimi \& Soltani 1999, Garcia \& Azambuja 2004). 
All experiments were repeated at least in triplicate with batches of 30 insects. The significance of the results was analyzed using ANOVA and Turkey's test (Armitage et al. 2002) according to Stats Direct Statistical Software, version 2.2.7 for Windows 98. Differences between treated and control insects were not considered to be statistically significant when $p>0.05$. Probability levels are specified in the Tables.

Any tested treatment interfered with an increase in the body weight or amount of excretion in $R$. prolixus nymphs compared to control groups. Also, no anti-feeding effects or malformations were observed (not shown). Table I demonstrates that all assayed doses induced significant mortality levels of treated insects $24 \mathrm{~h}$ after blood feeding with TFM. The highest levels of mortality were observed 30 days after feeding in a dose response manner. The most mortality was observed in the group treated with $5.0 \mathrm{mg} / \mathrm{mL}$ of blood $(43.3 \%$ and $96.6 \%$ at days 1 and 30 after blood meal, respectively). The intermoulting period simultaneously started after 12 days of feeding in both the control group and in the group treated with $0.05 \mathrm{mg} / \mathrm{mL}$ of blood. In the control group, the intermolting period started 12 days after feeding and finished 16 days after feeding. The intermoulting period lasted six days in the group treated with $0.05 \mathrm{mg} / \mathrm{mL}$ of blood. In the group treated with $0.05 \mathrm{mg} / \mathrm{mL}$, only $4.2 \%$ of treated nymphs reached the adult phase 18 days after feeding. All the insects that survived in the control group (79.1\%) became adults, yet $9.2 \%$ of insects remained as fifth-instar over-aged nymphs until the end of the experiments in the group treated with $0.05 \mathrm{mg} / \mathrm{mL}$ of blood meal. In the groups treated with $0.25,0.50$ and 5.0 $\mathrm{mg}$ of TFM $/ \mathrm{mL}$ of blood, all the insects that survived remained as over-aged fifth-instar nymphs until the end of observation $(11 \%, 6.7 \%$ and $3.4 \%$, respectively). In the topical treatment, the highest levels of mortality after 24 $\mathrm{h}$ were always observed in a dose response manner. The most effective dose (5.0 mg per insect) induced lethality in $91.3 \%$ and $100 \%$ of treated nymphs at days 1 and 30 after feeding, respectively. Considering the entire experiment, the highest levels of molt inhibition were obtained by topical treatment. If any nymph reached molt, there is no intermolting period since the nymphs remained permanently as over-aged fifth-instar.

Thus, $12.7 \%, 9.0 \%$ and $6.7 \%$ over-aged nymphs survived from the groups that were treated with $0.05,0.25$ or $0.50 \mathrm{mg}$ of TFM per insect, respectively (Table II). The lowest doses needed to obtain considerable biological effects were observed after continuous treatment. Also, considering the entire experiment, the highest levels of mortality 30 days after feeding were observed in the continuous treatment. Table III shows that $92.3 \%$, $93.2 \%, 96.3 \%$ and $100 \%$ of insects died in the groups treated with $0.007,0.035,0.070$ or $0.70 \mathrm{mg}$ of TFM per

\section{TABLE I}

Biological evaluation of the feeding treatment with triflumuron on the development of male Rhodnius prolixus fifth-instar nymph. The control insects were fully engorged on citrated whole human blood only, whereas experimental groups were fed on human blood added with Starycide ${ }^{\circledR}$ at concentrations from 0.05-5.0 mL

\begin{tabular}{lcccrr}
\hline Groups & $\begin{array}{c}\text { Mortality 24 h after } \\
\text { feeding (\%) }\end{array}$ & $\begin{array}{c}\text { Mortality 30 days after } \\
\text { feeding (\%) }\end{array}$ & $\begin{array}{c}\text { Intermolting period range } \\
\text { (days after feeding) }\end{array}$ & $\begin{array}{c}\text { Molt 30 days after } \\
\text { feeding (\%) }\end{array}$ & $\begin{array}{c}\text { Over-aged } \\
\text { nymphs (\%) }\end{array}$ \\
\hline Control & $7.6 \pm 1.2$ & $21 \pm 2.9$ & $12 / 16$ & $79 \pm 1$ & - \\
$0.05 \mathrm{mg} / \mathrm{mL}$ & $30 \pm 8.1^{a}$ & $86.6 \pm 12.4^{c}$ & $12 / 18$ & $4.2 \pm 1^{c}$ & $9.2^{c} \pm 0.1^{c}$ \\
$0.25 \mathrm{mg} / \mathrm{mL}$ & $23.3 \pm 18.8^{a}$ & $89 \pm 1.4^{c}$ & - & - & $11 \pm 0.8^{c}$ \\
$0.50 \mathrm{mg} / \mathrm{mL}$ & $33.3 \pm 16.9^{a}$ & $93.3 \pm 4.7^{c}$ & - & - & $6.7 \pm 2.1^{c}$ \\
$5.0 \mathrm{mg} / \mathrm{mL}$ & $43.3 \pm 16.9^{b}$ & $96.6 \pm 4.7^{c}$ & - & - & $3.4 \pm 1.8^{c}$ \\
\hline
\end{tabular}

letters following numbers point out difference between treated and control insects, since $\mathrm{p}>0.05$ were considered not statistically significant: $a: \mathrm{p}<0.01 ; b: \mathrm{p}<0.001 ; c: \mathrm{p}<0.0001$. Each group represents means $\pm \mathrm{SD}$ (percentage) of at least three experiments.

\section{TABLE II}

Biological evaluation of the topical treatment with triflumuron on the development of male Rhodnius prolixus fifth-instar nymph. The control insects were only fully engorged on citrated whole human blood only, whereas doses from 0.05-5.0 mg of Starycide ${ }^{\circledR}$ per insect were used for the topical treatment and applied directly to the ventral surface of the abdomen immediately after feeding

\begin{tabular}{lccccr}
\hline Groups & $\begin{array}{c}\text { Mortality 24 h after } \\
\text { feeding (\%) }\end{array}$ & $\begin{array}{c}\text { Mortality 30 days after } \\
\text { feeding (\%) }\end{array}$ & $\begin{array}{c}\text { Intermolting period range } \\
\text { (days after feeding) }\end{array}$ & $\begin{array}{c}\text { Molt 30 days after } \\
\text { feeding (\%) }\end{array}$ & $\begin{array}{c}\text { Over-aged } \\
\text { nymphs (\%) }\end{array}$ \\
\hline Control & $5.5 \pm 4.0$ & $25.6 \pm 3.2$ & $12 / 16$ & $74.4 \pm 2.8$ & - \\
$0.05 \mathrm{mg} /$ insect & $55.6 \pm 10.2^{a}$ & $87.3 \pm 2^{b}$ & - & - & $12.7 \pm 3.1^{b}$ \\
$0.25 \mathrm{mg} /$ insect & $73 \pm 2.4^{b}$ & $91 \pm 1.4^{b}$ & - & - & $9 \pm 3.6^{b}$ \\
$0.50 \mathrm{mg} /$ insect & $74 \pm 1.4^{b}$ & $93.3 \pm 2.8^{b}$ & - & - & $6.7 \pm 2.2^{b}$ \\
$5.0 \mathrm{mg} /$ insect & $91.3 \pm 4.1^{b}$ & $100^{b}$ & - & - & - \\
\hline
\end{tabular}

letters following numbers point out difference between treated and control insects, since $\mathrm{p}>0.05$ were considered not statistically significant: $(\mathrm{p}<0.01) ; a$ : $\mathrm{p}<0.001 ; b: \mathrm{p}<0.0001$. Each group represents means $\pm \mathrm{SD}$ (percentage) of at least three experiments. 


\section{TABLE III}

Biological evaluation of the continuous treatment with triflumuron on the development of male Rhodnius prolixus fifth-instar nymph. The control insects were fully engorged on citrated whole human blood only, whereas Starycide ${ }^{\circledR}$ was applied at the bottom of Petri dishes to obtain final concentrations from $0.007-0.70 \mathrm{mg} / \mathrm{cm}^{2}$; experimental nymphs were then placed on the treated surface immediately after feeding and covered with a Petri dish

\begin{tabular}{lccccc}
\hline Groups & $\begin{array}{c}\text { Mortality 24 h after } \\
\text { feeding (\%) }\end{array}$ & $\begin{array}{c}\text { Mortality 30 days after } \\
\text { feeding (\%) }\end{array}$ & $\begin{array}{c}\text { Intermolting period range } \\
\text { (days after feeding) }\end{array}$ & $\begin{array}{c}\text { Molt 30 days after } \\
\text { feeding (\%) }\end{array}$ & $\begin{array}{c}\text { Over-aged } \\
\text { nymphs (\%) }\end{array}$ \\
\hline Control & $5.0 \pm 3.1$ & $18.6 \pm 8.3$ & $12 / 16$ & $81.4 \pm 1.5$ & - \\
$0.007 \mathrm{mg} / \mathrm{cm}^{2}$ & $36.6 \pm 12.4^{a}$ & $92.3 \pm 3.2^{c}$ & $15 / 20^{a}$ & $3.8 \pm 1.6^{c}$ & $3.8 \pm 1.8^{c}$ \\
$0.035 \mathrm{mg} / \mathrm{cm}^{2}$ & $37.3 \pm 12.4^{a}$ & $93 \pm 2.4^{c}$ & $15 / 20^{a}$ & $5.0 \pm 2.6^{c}$ & $5.0 \pm 2.7^{c}$ \\
$0.070 \mathrm{mg} / \mathrm{cm}^{2}$ & $40 \pm 8.1^{a}$ & $96.3 \pm 5.5^{c}$ & $18 / 22^{b}$ & $1.9 \pm 1.2^{c}$ & $5.8 \pm 1^{c}$ \\
$0.70 \mathrm{mg} / \mathrm{c}^{2}$ & $60 \pm 8.1^{b}$ & $100^{c}$ & - & - & - \\
\hline
\end{tabular}

letters following numbers point out difference between treated and control insects since $\mathrm{p}>0.05$ were considered not statistically significant: $a: \mathrm{p}<0.01 ; b: \mathrm{p}<0.001 ; c: \mathrm{p}<0.0001$. Each group represents means $\pm \mathrm{SD}$ (percentage) of at least three experiments.

$\mathrm{cm}^{2}$, respectively, in 30 days after feeding. The intermolting period started three-five days late - in a dose response manner - and extended until 20 days after treatment in the groups treated with 0.007 and $0.035 \mathrm{mg}$ of $\mathrm{TFM} / \mathrm{cm}^{2}$, and 22 days after treatment in the group treated with 0.070 of TFM $/ \mathrm{cm}^{2}$. Only $3.8 \%, 5 \%$ and $1.9 \%$ of the treated nymphs reached the adult stage and $3.8 \%, 5 \%$ and $5.8 \%$ remained as over-aged nymphs after continuous treatment with $0.007,0.035$ and $0.070 \mathrm{mg}$ of TFM $/ \mathrm{cm}^{2}$, respectively. Thus, the lowest number of over-aged nymphs and the highest level of molting of survived nymphs were observed after continuous treatment.

Insecticides are known for their rapid action and are effective control agents for reducing vector borne diseases. Insecticides also have side effects, insects develop resistance against them, and they are toxic to beneficial insects. Thus, there has been promotion of environmentally friendly pesticides and IGRs as part of modern integrated vector control programs since they are ecologically safe, degradable and target specific (Hajjar 1985, Isman 2005, Senthil Nathan et al. 2006). Chitin is one of the most common polysaccharides in nature and mainly found in cuticles of arthropods, cellular walls of fungi and nematodes. This polymer is considered to be one of the most important components in the rigidity of insect cuticles. In this way, the BPUs block molting in insects by disrupting the cuticle deposition (Degheele 1990) and are effective growth regulators on several insect orders (Merzendorfer 2006). TFM, a recent developed BPU derivate, is implicated in the interference of insect chitin biosynthesis. Therefore, these compounds have been the target of intensive study and several physiological effects have been described in agricultural plagues and insect vectors of diseases. Our data obtained by experiments with $R$. prolixus fifth-instar nymphs demonstrate that TFM is able to induce high levels of mortality for all treatment methods assayed. Moreover, an extended intermolting period and molt inhibition associated with over-aged nymphs were also observed. On the other hand, feeding treatment induced low mortality levels when compared with both topical and continuous treatment, which perhaps suggests that the compound was metabolized more effectively by the insects' digestive system despite the fact that alterations related to body weight or level of excretion were not detected. Continuous treatment induced the highest level of mortality 30 days after feeding, but also induced the lowest number of over-aged nymphs and the highest level of molting of nymphs that survived treatment. This fact could be also related with environmental biodegradation of the compound after a short time and constitutes a beneficial indication in field conditions for integrated vector control programs because of its low risk to non-target organisms (Sulaiman et al. 1994, Isman 2005). Moreover, very low doses of $0.007,0.035$ and $0.070 \mathrm{mg} / \mathrm{cm}^{2}$ were able to disrupt insect development. For example, a single dose of $0.70 \mathrm{mg} / \mathrm{cm}^{2}$ were able to induce $100 \%$ mortality 30 days after feeding, which indicates that this concentration is appropriate for control programs against triatomine species. Topical treatment seems to be very efficient since it induced the highest levels of mortality after $24 \mathrm{~h}$ and the highest level of molt inhibition and number of overaged nymphs. Furthermore, a dose response manner was observed for most TFM effects on R. prolixus nymphs after all treatments assayed. Nowadays, the chemical insecticide constitutes the most important tool for vector population control programs, although several of them also induced resistance on the target insects. In search of safer technologies that involve the development of compounds that have selective action against target vectors, low risk for non-target organisms, and safety for the environment, growth regulators, especially BFUs, represent a promising new eco-friendly strategy (Isman 2005, WHO 2006). Thus, our data suggests that TFM and perhaps other chitin synthesis inhibitors may be considered as potential tools for integrated vector control programs against hematophagous triatomine species.

\section{ACKNOWLEDGMENT}

To Professor Shaun Walker, for the English revision of the manuscript.

\section{REFERENCES}

Amir OG, Peveling R 2004. Effect of triflumuron on brood development and colony survival of free-flying honeybee, Apis mellifera L. J Appl Entomol 128: 242-249. 
Armitage P, Berry G, Matthews JNS 2002. Comparision of several groups and experimental design. In P Armitage, Statistical Methods in Medical Research, 4th ed., Blackwell Science Publishing, Oxford, p. 208-256.

Chagas C 1909. Nova tripanosomíase humana. Estudos sobre a morfologia e o ciclo evolutivo do Schizotrypanum cruzi n. gen.,n. sp., agente etiológico de nova entidade mórbida do homem. Mem Inst Oswaldo Cruz 1: 159-218.

Deghele D 1990. Chitin shynthesis inhibitiors: effects on cuticle and components. In J Casida, Pesticides and alternatives, Elsevier, Amsterdam, p. 377-388

Garcia ES, Azambuja P 2004. Lignoids in insects: chemical probes for the study of ecdysis, excretion and Trypanosoma cruzi-triatomine interaction. Toxicon 44: 431-440.

Garcia ES, Azambuja P, Contreras V 1984. Large-scale rearing of Rhodnius prolixus and production of metacyclic trypomastigotes of Trypanosome cruzi. In CM Morel, Genes and Antigens of Parasites, a Laboratory Manual, 2nd ed., Fundação Oswaldo Cruz, Rio de Janeiro, p. 44-47.

Garcia ES, Ratcliffe NA, Whitten MM, Gonzalez MS, Azambuja P 2007. Exploring the role of insect host factors in the dynamics of Trypanosoma cruzi-Rhodnius prolixus interactions. $J$ Insect Physiol 53: 11-21.

Hajjar N. 1985. Chitin synthesis inhibitors as insecticides. In DH Hus- ton, TR Roberts, Insecticides, John Wiley and Sons, New York, p. 275-310.

Isman MB 2005. Botanical insecticides, deterrents, and repellents in modern agriculture and increasingly regulated world. Annu Rev Entomol 51: 45-66.

Langley PA 1995. Evaluation of the chitin synthesis inhibitor triflumuron for controlling the tsetse Glossina morsitans morsitans (Diptera: Glossinidae). Bull Entomol Res 85: 495-500.

Merzendorfer H 2006. Insect chitin shyntases: a review. $J$ Comp Physiol B: Biochem Sys Env Physiol 176: 1-15.

Rehimi N, Soltani N 1999. Laboratory evaluation of Alsystin, a chitin synthesis inhibitor, against Culex pipiens pipiens L. (Diptera: Culicidae): effects on development and cuticle secretion. J Appl Entomol 123: 437-441.

Senthil-NathanS, SavithaG, GeorgeDK,NarmadhaA,SuganyaL, Chung PG 2006. Efficacy of Melia azedarach L. extract on the malarial vector Anopheles stephensi Liston (Diptera: Culicidae). Biores Tech 97: 1316-1323.

Sulaiman S, Jeffery J, Sohadi RA 1994. Residual efficacy of triflumuron against the dengue vector, Aedes albopictus (Skuse). Bull Soc Vec Ecol 19: 111-114.

WHO - World Health Organization 2006. Pesticides and their application: for the control of vectors and pests of public health importance, 6th ed., WHO, Genebra, 1406 pp. 